\title{
A distal region of the human TGMI promoter is required for expression in transgenic mice and cultured keratinocytes Marjorie A Phillips ${ }^{1}$, Bart A Jessen ${ }^{1,3}$, Ying Lu ${ }^{1,4}$, Qin Qin ${ }^{1}$, Mary E Stevens ${ }^{2}$ and Robert H Rice*1
}

Address: ${ }^{1}$ Department of Environmental Toxicology, University of California, Davis, CA 95616-8588 USA, ${ }^{2}$ Bayer Biotechnology, Berkeley, CA 94701 USA, ${ }^{3}$ Pfizer Global Research and Development, San Diego, CA 92121 USA and ${ }^{4}$ Department of Internal Medicine, University of California Davis Medical Center, Sacramento, CA 95817 USA

Email: Marjorie A Phillips - maphillips@ucdavis.edu; Bart A Jessen - bart.jessen@pfizer.com; Ying Lu - yilu@ucdavis.edu; Qin Qin - qaqin@ucdavis.edu; Mary E Stevens - mary.stevens.b@bayer.com; Robert H Rice* - rhrice@ucdavis.edu

* Corresponding author

Published: 05 April 2004

BMC Dermatology 2004, 4:2
Received: 28 September 2003

Accepted: 05 April 2004

This article is available from: http://www.biomedcentral.com/I47I-5945/4/2

(C) 2004 Phillips et al; licensee BioMed Central Ltd. This is an Open Access article: verbatim copying and redistribution of this article are permitted in all media for any purpose, provided this notice is preserved along with the article's original URL.

\begin{abstract}
Background: TGMI(transglutaminase I) is an enzyme that crosslinks the cornified envelope of mature keratinocytes. Appropriate expression of the TGMI gene is crucial for proper keratinocyte function as inactivating mutations lead to the debilitating skin disease, lamellar ichthyosis. TGMI is also expressed in squamous metaplasia, a consequence in some epithelia of vitamin A deficiency or toxic insult that can lead to neoplasia. An understanding of the regulation of this gene in normal and abnormal differentiation states may contribute to better disease diagnosis and treatment.
\end{abstract}

Methods: In vivo requirements for expression of the TGMI gene were studied by fusing various lengths of promoter DNA to a reporter and injecting the DNA into mouse embryos to generate transgenic animals. Expression of the reporter was ascertained by Western blotting and immunohistochemistry. Further delineation of a transcriptionally important distal region was determined by transfections of progressively shortened or mutated promoter DNA into cultured keratinocytes.

Results: In vivo analysis of a reporter transgene driven by the TGMI promoter revealed that 1.6 kilobases, but not I.I kilobases, of DNA was sufficient to confer tissue-specific and cell layerspecific expression. This same region was responsible for reporter expression in tissues undergoing squamous metaplasia as a response to vitamin A deprivation. Mutation of a distal promoter API site or proximal promoter CRE site, both identified as important transcriptional elements in transfection assays, did not prevent appropriate expression. Further searching for transcriptional elements using electrophoretic mobility shift (EMSA) and transfection assays in cultured keratinocytes identified two SpI elements in a transcriptionally active region between - I.6 and - I.4 kilobases. While mutation of either SpI site or the API site singly had only a small effect, mutation of all three sites eliminated nearly all the transcriptional activity.

Conclusions: A distal region of the TGMI gene promoter, containing API and SpI binding sites, is evolutionarily conserved and responsible for high level expression in transgenic mice and in transfected keratinocyte cultures. 


\section{Background}

Transglutaminases, including the product of the TGM1 gene, catalyze formation of $\varepsilon$-( $\gamma$-glutamyl)-lysine crosslinks in proteins and thereby stabilize biological structures [1]. In epidermis, TGM1 is required for the formation of the cross-linked envelope. Point mutations in the gene that cause deficits in enzyme activity can give rise to lamellar ichthyosis. [2-5], a disease characterized by lack of a normal barrier to dehydration [6]. Further analysis of the promoter may assist in evaluating cases where promoter sequence alterations are suspected to yield defective TGM1 expression $[7,8]$.

TGM1 is normally expressed in the suprabasal cells of stratifying epithelia such as epidermis, the upper digestive tract, the female lower genital tract and in the endometrial epithelium late in pregnancy [9]. It is also expressed as a result of squamous metaplasia in the trachea induced by vitamin A deprivation [10] and in a number of epithelial cell types, including those from bladder and endometrium, induced by culture on plastic [11]. Transgenes incorporating $2.9 \mathrm{~kb}$ of the rabbit [12] or $2.5 \mathrm{~kb}$ of the human [13] TGM1 promoters have been shown to exhibit appropriate tissue-specific and cell layer-specific expression in mice. Transfection experiments in cultured human, rabbit and rat keratinocytes have identified regions that are important for high transcriptional activity $[12,14,15]$. One of two major regions, at $-1.5 \mathrm{~kb}$ in the distal promoter, contains a consensus AP1 binding site, and the other region, in the proximal promoter at $-0.45 \mathrm{~kb}$, contains a CRE-like binding site. In this study we assessed the in vivo activities of these regions of the TGM1 promoter in transgenic mice fed a normal diet and after vitamin A deprivation that induced squamous metaplasia.

\section{Methods \\ Transgenic mice}

The TGM1 promoter/human involucrin reporter fusion genes used to generate transgenic mice were made by first cutting the human involucrin genomic clone p $\lambda \mathrm{I}-3 \mathrm{H} 6 \mathrm{~B}$ [16] with HinCII, which cleaves the gene within the second exon at 15 bp 5 ' to the translation start site. The DNA was ligated to a Bgl II linker and subsequently cut with Bgl II and BamH I to excise a $2.5 \mathrm{~kb}$ piece of DNA containing the entire involucrin coding region. This DNA was gel purified and subcloned into the Bgl II and BamH I sites of the pGL3 Basic vector (Promega) to generate the reporter plasmid, pINV, with involucrin coding sequence substituted for luciferase. The TGM1 promoter was amplified with Pfu polymerase (Stratagene) using human TGM1 clone TGI [17] as template and an upstream primer, 5' base at -2200 (containing an untemplated Sal I restriction site) and a downstream primer, 3 ' base at +67 (containing an untemplated Bgl II restriction site). The promoter PCR product was completely sequenced to verify that no errors had been introduced by PCR, then cut with Sal I and Bgl II and ligated to pINV which had been cut with Xho I and Bgl II. Transgenes were excised from the plasmid by cutting with Kpn I/Sal I, Spe I/Sal I or Hind III/Sal I to generate TG2.2, TG1.1 and TG0.3, respectively. TG1.6 was constructed by substituting a sequence verified KpnI/ EcoRV restriction fragment from TG1.6 in pGL3 (described below) for the KpnI/EcoRV fragment of the TG2.2 transgene. TG2.2/AP1m and TG/2.2CREm with mutated AP1 and CRE sites, respectively, were made by subcloning restriction fragments containing the mutations (mutagenesis described in [14]) into TG2.2. The regions containing the subcloned restriction fragments were sequence verified. DNA for microinjection was purified by agarose gel electrophoresis and Schleicher and Schuell Elutip columns. Transgenic mice were created using standard pronuclear injection techniques. Multiple founders were obtained for each transgene construct and all resulting progeny were maintained in a purebred FVB strain. The F1 or later generations were used for analysis.

\section{Animal screening}

Presence of the transgene was detected by PCR amplification of a portion of the chimeric sequences from mouse genomic DNA. The mouse DNA was prepared by a standard method [18]. Briefly, approximately $5 \mathrm{~mm}$ of mouse tail biopsy was digested overnight at $55^{\circ} \mathrm{C}$ in lysis buffer (50 mM Tris, pH 8.0, 100 mM EDTA, 0.125\% SDS, $1 \mathrm{mg} /$ $\mathrm{ml}$ proteinase $\mathrm{K})$. Samples were extracted twice with phenol/chloroform (1:1), once with chloroform and precipitated with ethanol. Each sample was reconstituted in 200 $\mu \mathrm{l}$ of $10 \mathrm{mM}$ Tris buffer ( $\mathrm{pH} 8$ ) containing $1 \mathrm{mM}$ EDTA resulting in a final DNA concentration of 50 to $150 \mathrm{ng} / \mu \mathrm{l}$. One $\mu$ l of genomic DNA was used as the template for PCR. Primers were designed to anneal to the TGM1 promoter at -0.2 kb (forward primer 5'-GGTGCCAGGGGCCATCACAG) and to the 5 ' end of the involucrin coding region (reverse primer 5'-GGCATGGGGGAGGCAGTGG), resulting in a 460 bp product, identified by agarose gel electrophoresis.

\section{Western blots}

Tissues were homogenized in $0.5 \mathrm{ml}$ of lysis buffer (20 $\mathrm{mM}$ Tris, $\mathrm{pH} 7.5,20 \mathrm{mM}$ EDTA, 0.1\% SDS) in a ground glass homogenizer. After centrifugation for $15 \mathrm{~min}$ at $10,000 \times \mathrm{g}$ at $4^{\circ} \mathrm{C}$, the supernatant was collected and stored at $-80^{\circ} \mathrm{C}$. Protein concentration was determined using Coomassie G-250 (Biorad) [19], and $5 \mu \mathrm{g}$ of protein from each tissue were separated by SDS polyacrylamide gel electrophoresis. Proteins were electrophoretically transferred to a nitrocellulose membrane using a semi-dry blotter (Biorad). The human involucrin reporter was detected using rabbit anti-human involucrin antiserum and ECL Plus chemiluminescence kit (Amersham). 


\section{Immunohistochemistry}

Mouse tissues were fixed in phosphate buffered saline containing $10 \%$ formalin, embedded in paraffin and sectioned. The sections were incubated with rabbit antihuman involucrin antiserum, followed by biotin-labeled anti-rabbit antibody, then streptavidin linked to horseradish peroxidase. Sections were stained with 3,3'-diaminobenzidine (Biorad) [20] and counter-stained with hematoxylin. Two to five independent founder lines were examined for each construct. Use of human involucrin as a reporter is a departure from the commonly used $\beta$-galactosidase, luciferase, or green fluorescent protein. This protein was chosen since very specific antibodies to it are available [21]. The antiserum recognized the antigen in fixed, paraffin-embedded tissues, did not cross-react with the mouse involucrin protein, and reacted with a single protein in western blotting. Immunohistochemistry showed that, like endogenous transglutaminase 1 protein [9], the involucrin reporter is expressed in the suprabasal layers of the epidermis and increased as the cells moved toward the surface. The observed staining pattern resembled that of involucrin in human epidermis in that the cornified layers did not stain well, presumably because most of the involucrin immunoreactivity was masked by cross-linking.

\section{Cell culture}

The keratinocyte lines used were normal human epidermal cells (hEp) derived from foreskin, the spontaneously immortalized SIK line, derived from human foreskin epidermis [22], the human squamous cell carcinoma line SCC9 [23], the rEp line derived from rat epidermis [24], and the rB line from rat bladder epithelium [11]. Cells were cultured in the presence of a lethally irradiated 3T3 feeder layer [25] using a 3:1 mixture of Dulbecco's modified Eagle's and Ham's F-12 media, supplemented with $5 \%$ fetal bovine serum, $0.4 \mu \mathrm{g} / \mathrm{ml}$ cortisol, $5 \mu \mathrm{g} / \mathrm{ml}$ insulin and transferrin, $20 \mathrm{pM}$ triiodothyronine and $0.18 \mathrm{mM}$ adenine [26]. Medium for hEp and SIK cultures was also supplemented with $10 \mathrm{ng} / \mathrm{ml}$ cholera toxin upon inoculation and $10 \mathrm{ng} / \mathrm{ml}$ epidermal growth factor starting at the first medium change until confluence. All cell lines express easily detectable levels of TGM1 mRNA on Northern blots ([27] and our unpublished results).

\section{Transfections}

Cells were inoculated in 12-well plates and transfected two to four days later, when the small colonies covered about $50 \%$ of the surface of the wells. SIK, hEp and rEp cultures were transfected with calcium phosphate-DNA coprecipitates [28] using $2.5 \mu \mathrm{g}$ of reporter DNA, $2.5 \mu \mathrm{g}$ of sonicated salmon sperm DNA and 1 ng of pRL-cytomegalovirus (Promega) per well. The precipitates were incubated with the cells overnight, then the medium was changed. Cell extracts were prepared four days later and stored frozen. The $\mathrm{rB}$ cell line was transfected using Fugene reagent (Roche) according to the manufacturer's protocol with $1.5 \mu$ l Fugene reagent, $0.5 \mu \mathrm{g}$ of reporter DNA and $10 \mathrm{ng}$ of pRL-cytomegalovirus per well in $1 \mathrm{ml}$ of serum free DMEM. After 3-4 hours the medium was replaced with growth medium. After two days, the cells were harvested.

The reporter DNAs contained pieces of the TGM1 promoter which were amplified by PCR using primers with added restriction sites at the $5^{\prime}$ end, and cloned into the pGL3 vector (Promega). All terminated at the 3 ' end at +67 relative to the transcription start site. Internal deletions were made by fusing PCR products of different amplified regions of the promoter to a TGM1 minimal promoter $(-90$ to +67$)$. Promoters containing mutated transcription factor binding sites were made using the Stratagene QuikChange Site-directed Mutagenesis kit. Mutated sites were identified by sequencing and the promoters were excised and subcloned back into the pGL3 vector. Firefly luciferase (driven by the TGM1 promoter) and Renilla luciferase (used to normalize for differing transfection efficiencies) were assayed with the dual luciferase kit from Promega.

\section{Electrophoretic mobility shift assay (EMSA)}

Nuclear extracts were prepared by minor modification of a standard method [29,30]. Probes were made by labeling annealed oligonucleotides containing a single added 5' G overhang with the Klenow fragment of DNA polymerase I (New England Biolabs) in the presence of ${ }^{32} \mathrm{P}$ dCTP (Perkin Elmer) or, for the consensus Sp1 site (Stratagene), by end-labelling with ${ }^{32} \mathrm{P}$ ATP and T4 polynucleotide kinase. Binding reactions $(20 \mu \mathrm{l})$ contained 5-10 $\mu \mathrm{g}$ nuclear extract protein and $500 \mathrm{ng}$ of poly [d(I-C)-poly(dI-C)] in a solution of $12.5 \mathrm{mM}$ HEPES, $\mathrm{pH} 7.9$ (at $4^{\circ} \mathrm{C}$ ); $0.2 \mathrm{mM}$ EDTA; $0.01 \%$ NP-40; $0.5 \mathrm{mM}$ dithiothreitol; $100 \mathrm{mM}$ $\mathrm{NaCl}$ and $10 \%$ glycerol. After a 10 minute incubation at room temperature, $10 \mathrm{fmol}$ of labeled probe was added and incubation was continued for 10 minutes. DNA protein complexes were separated on $4 \%$ polyacrylamide gels in 0.5X TBE buffer (final concentrations: $22.5 \mathrm{mM}$ Trisborate, $0.5 \mathrm{mM}$ EDTA). In some experiments competitor oligonucleotides were added at 100 fold molar excess. Antibody competition for Sp1 and Sp3 binding was done by adding 1 or $2 \mu \mathrm{g}$ of antibody (Santa Cruz, sc-59X or sc644 ) to binding reactions, followed by incubation on ice for $1 \mathrm{hr}$ before probe addition.

\section{Results}

\section{TGMI promoter activity in transgenic mice}

The importance for proper in vivo expression of the distal and proximal TGM1 promoter regions, and of specific AP1 and CRE elements located therein, was tested using (1) different lengths of TGM1 promoter DNA, 

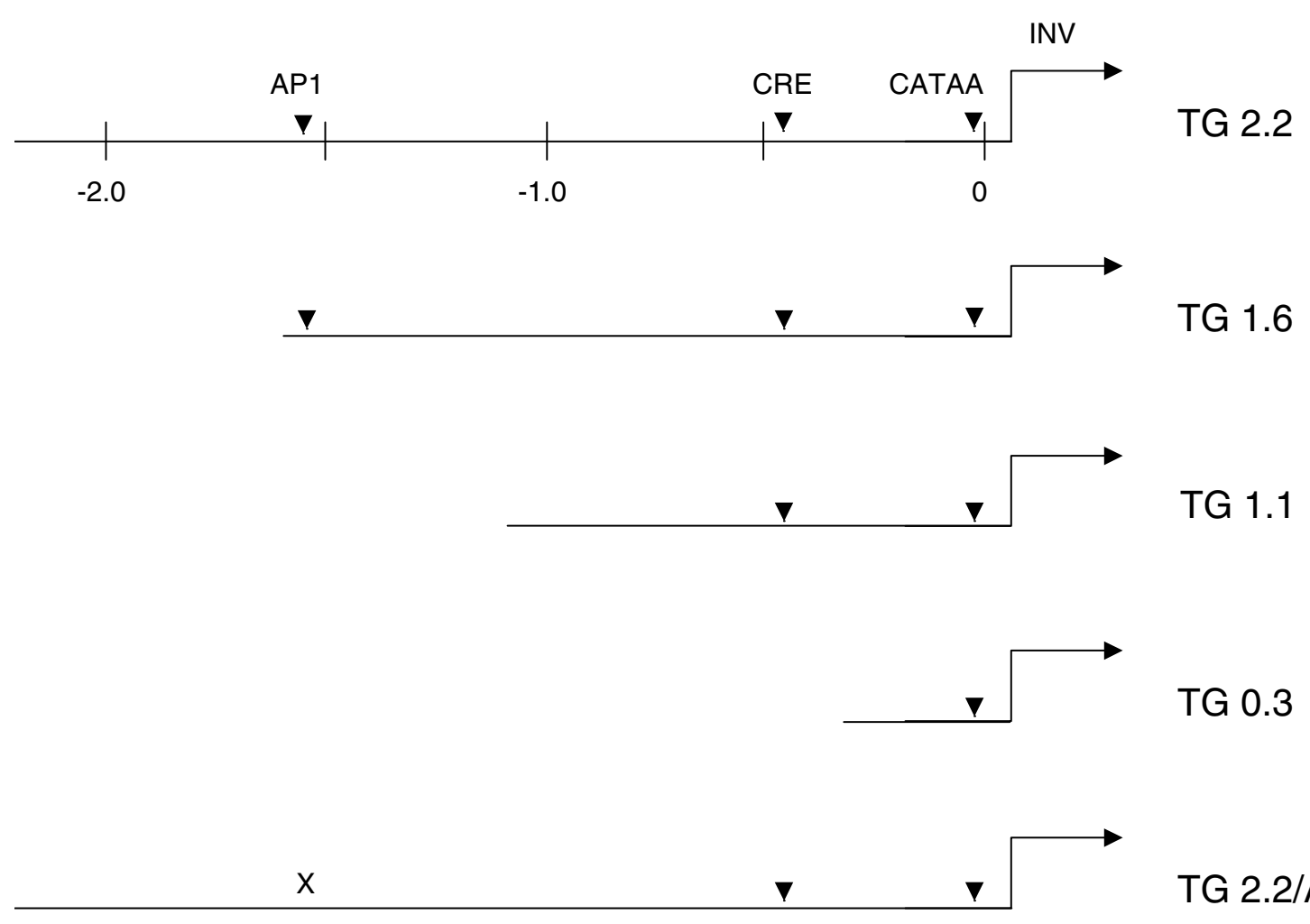

TG 2.2/AP1m

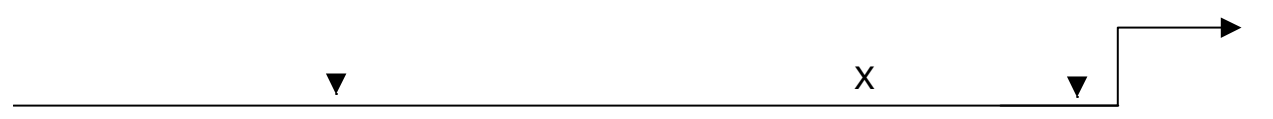

TG 2.2/CREm

\section{Figure I}

Schematics of transgenes The TGMI promoter regions present in the six transgenes are depicted. Numbers indicate distances in kilobase pairs from the transcription start site, which is designated as 0 . The promoter constructs all terminated at the $3^{\prime}$ end at base pair +67 relative to the transcription start site. Arrowheads show the locations of API, CRE and CATAA (TATA-like) elements, with mutated sites indicated by an $\mathrm{X}$. The position and direction of transcription of the human involucrin reporter (INV) are shown by an arrow.

progressively shortened from the distal (5') end and (2) the TGM1 promoter with mutated AP1 or CRE binding sites. A schematic of the different TGM1 transgenes is shown in Fig 1. The first transgene we studied, TG2.2, contained $2.2 \mathrm{~kb}$ of TGM1 promoter DNA, which includes both the AP1 and CRE regulatory elements that were identified in earlier transfection experiments. TG1.6 eliminates $0.6 \mathrm{~kb}$ of DNA, but still includes both of those elements. Shorter promoters were chosen to eliminate the AP1 site (TG1.1) or both the AP1 and CRE elements (TG0.3). TG2.2/CREm and TG2.2/AP1m contain $2.2 \mathrm{~kb}$ of promoter DNA with mutations that have been shown to destroy the binding activities of the CRE and AP1 sites, respectively, in electrophoretic mobility shift assays (EMSA) [14].
TGM1 promoter activity in various tissues from animals carrying each of the 6 different transgenes was first determined by Western blotting, using the reporter antibody as a probe. In positive tissues, the reporter was visualized as a single prominent band, scored as plus (+) in Table 1. Other tissue extracts showed no reactivity with the antibody, even after extended exposure times, and are scored as minus (-). We conclude that $1.6 \mathrm{~kb}$ of TGM 1 promoter is sufficient to confer tissue specific expression since only stratified epithelia gave strong positive signals in all of the TG2.2 and TG1.6 founder lines (10 in total for both constructs). Transgenes with shorter promoters (1.1 and 0.3 $\mathrm{kb}$ of DNA) were consistently negative for reporter expression on Western blots of extracts from all tissues examined ( 5 of 5 total founders). AP1 and CRE mutations alone did 
Table I: Summary of tissue reactivity with reporter antibody on western blots'

\begin{tabular}{|c|c|c|c|c|c|c|}
\hline Transgene & $2.2(6)$ & I.6 (4) & I.I (3) & $0.3(2)$ & APImut (2) & CREmut (5) \\
\hline Footpad & $+(5)$ & $+(6)$ & $-(4)$ & $-(2)$ & $+(4)$ & $+(8)$ \\
\hline Esophagus & $+(5)$ & $+(5)$ & $-(3)$ & $-(3)$ & $+(4)$ & $+(8)$ \\
\hline Forestomach & $+(5)$ & $+(5)$ & $-(3)$ & $-(2)$ & $+(4)$ & $+(7)$ \\
\hline Vagina & $+(4)$ & $+(5)$ & $-(5)$ & $-(4)$ & $+(3)$ & $+(5)$ \\
\hline Tongue & $+(6)$ & $+(5)$ & $-(4)$ & $-(2)$ & $+(5)$ & $+(10)$ \\
\hline Uterus (preg) & $+(I)$ & $+(I)$ & $-(5)$ & $-(3)$ & $+/-(2)$ & $+(2)$ \\
\hline Bladder & $-(5)$ & $-(5)$ & $-(4)$ & $-(2)$ & $-(3)$ & $+/-(10)$ \\
\hline Heart & $-(4)$ & $-(5)$ & $-(4)$ & $-(2)$ & $-(4)$ & $+/-(10)$ \\
\hline Liver & $\mathrm{T}(10)$ & $-(5)$ & $-(4)$ & $-(2)$ & $-(4)$ & $-(10)$ \\
\hline Kidney & $-(10)$ & $-(5)$ & $-(4)$ & $-(2)$ & $-(4)$ & $-(7)$ \\
\hline
\end{tabular}

IObserved immunoreactivites are reported as positive + (strong); +/- (weak), - (negative) for no detectable immunoreactivity, or T (trace) for barely detectable. These entries are followed by numbers in parentheses which indicate the number of times each tissue was assayed. Results for each line are the collective outcome of evaluation of tissue extracts derived from 2 or more founders, except for pregnant uterus (one or more). For variable staining in mutant CRE and API mice, the reported result is for the majority of animals. The number of founder lines obtained for each construct is given in parentheses beside the construct name (Top line).

not prevent tissue specific expression of the reporter, with one exception. One of the TG2.2/AP1m founders was negative for reporter expression in all tissues and has been excluded from the analysis. It is not abnormal to find an occasional nonexpresser, generally assumed to occur in these sorts of studies due to repressive effects of chromosomal DNA surrounding the integration site. However, when the CRE element was mutated some low level expression was observed in heart and bladder tissue where TGM1 protein is not normally expressed. It is possible that additional elements not included in these constructs are required for complete suppression of ectopic gene activity.

Endometrial epithelium of the uterus has been shown to express TGM1 late in pregnancy in the rat [9]. This was also observed for reporter expression in the transgenic mice. The general promoter regions required for endometrial expression were the same as those required for expression in stratified squamous epithelia (2.2 and 1.6 $\mathrm{kb}$, but not shorter promoters).

We next examined reporter expression by immunohistochemistry to determine if the promoters employed conferred cell layer appropriate expression. TGM1 is not normally expressed in basal cells of stratified squamous epithelia, but appears in the upper spinous and granular layers. When sections from tissues that were positive for reporter expression on Western blots were examined by immunoperoxidase reaction, an intense brown staining was observed in upper layers, but not in basal cells of epidermis (footpad), oral epithelium (tongue), esophagus, forestomach or vagina. Fig 2 shows a representative section of footpad epidermis. Tissues or transgenes that were negative by Western blotting lacked this strong staining (not shown). The results are fully consistent with the pre- viously reported tissue and cell layer specific distribution of transglutaminase 1 in the rat obtained by immunohistochemistry using the monoclonal antibody B.C1 [9]. We conclude that the same general promoter regions that confer tissue specificity are also responsible for cell layerspecific expression.

\section{TGMI promoter in squamous metaplasia}

To determine which promoter regions are required for TGM1 expression in epithelia undergoing squamous metaplasia, mice were fed a diet lacking vitamin A. Pregnant females were put on the deficient diet and pups were kept on the diet for 7-8 weeks after weaning. At that time they began to exhibit ill effects of the diet and were sacrificed and tissues dissected for immunohistochemistry. Striking pathologies were observed in the uterus in most animals and in bladder in some animals. In the uterus, in addition to the normal uniform single layer of endometrial cells, occasional nodules of cells numerous layers thick were observed throughout the endometrium in vitamin A deficient animals (Fig 3B). These were immunoreactive using antisera to the human involucrin reporter (Fig $3 \mathrm{~A}$ ) and to mouse keratin 5 (not shown) in the TG2.2, 1.6, 2.2/CREm and 2.2/AP1m transgenic mice. Similar nodules were observed in the TG1.1 mice, but reporter staining was absent (not above background levels observed in stained tissue sections from nontransgenic mice). In several animals, bladder epithelium from deficient animals with borderline departure from normal histology also stained for the reporter (Fig 3C). Bladder tissue was unstained in animals fed standard mouse chow (not shown). In extreme cases, regions of the bladder epithelium strained strongly where the epithelium was visibly stratified and desquamated cells were observable (Fig 3D). The proximal urethra also stained intensely in most 


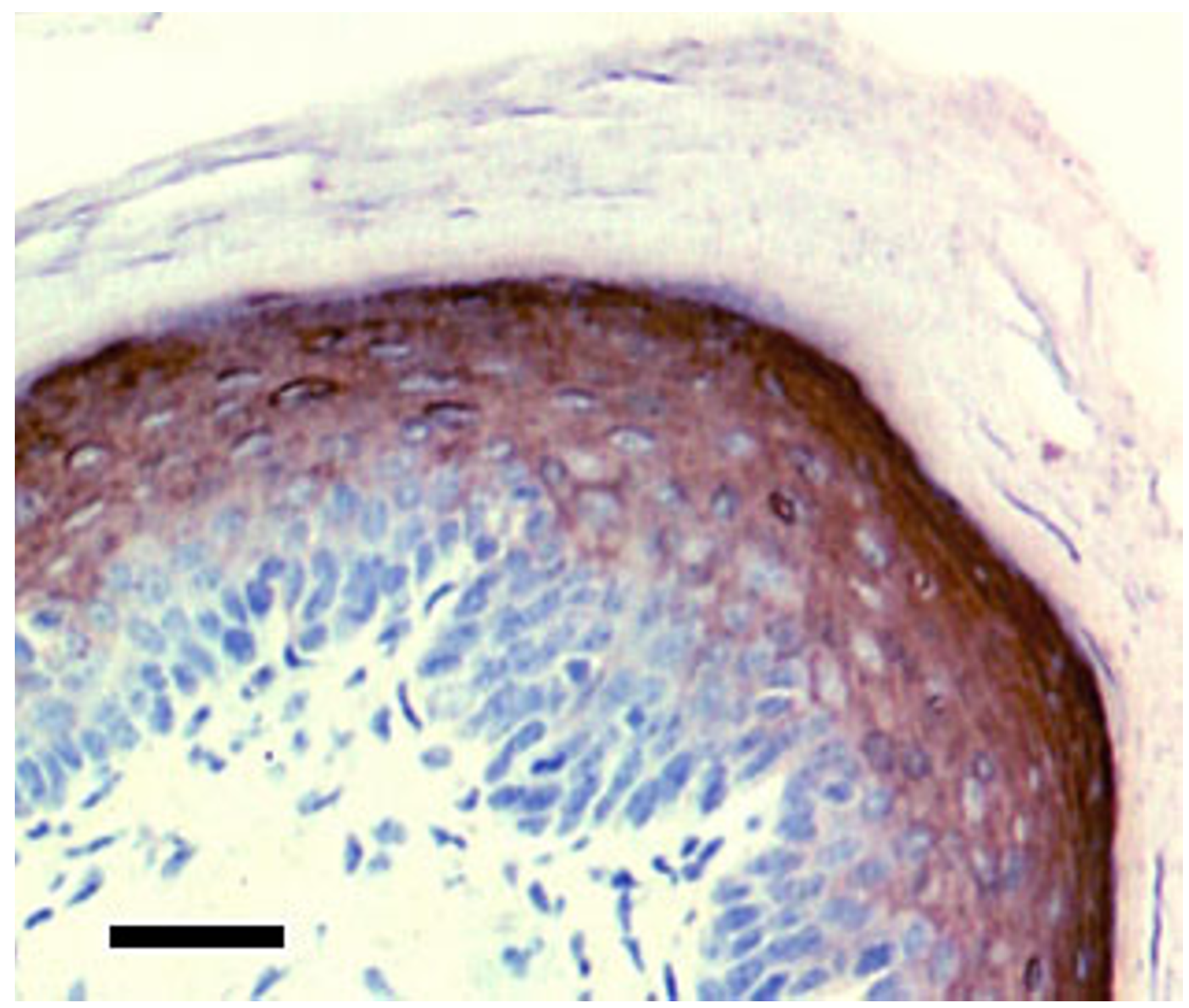

Figure 2

Footpad skin section from transgenic mouse TGI.6 immunostained for the human involucrin reporter Brown peroxidase staining is evident only in the upper spinous layer of epidermis; nuclei are counterstained with hematoxylin. Scale bar: $30 \mu \mathrm{m}$.

deficient animals, but not in animals fed the normal diet (not shown). Hence, the same promoter regions that conferred reporter expression in normal stratified squamous epithelia were active in the process of squamous metaplasia.

\section{Delineating regions of TGMI distal promoter required for transcriptional activity}

Since the region between -1.6 and $-1.1 \mathrm{~kb}$ was required for tissue specific and cell layer (differentiation state) specific transcriptional activity, it was examined in more detail in transfection experiments to define further the elements required for promoter activity. Initially, different regions of the TGM1 promoter fused to firefly luciferase reporter were transfected into normal human epidermal cultures (hEp) and into three different keratinocyte cell lines (Table 2). The results were qualitatively similar in all four keratinocyte cultures. Note in particular the importance of the distal region ( -1.0 to $-2.2 \mathrm{~kb})$ in all of the cultures. For further promoter mapping, we chose to use the rB cell line 

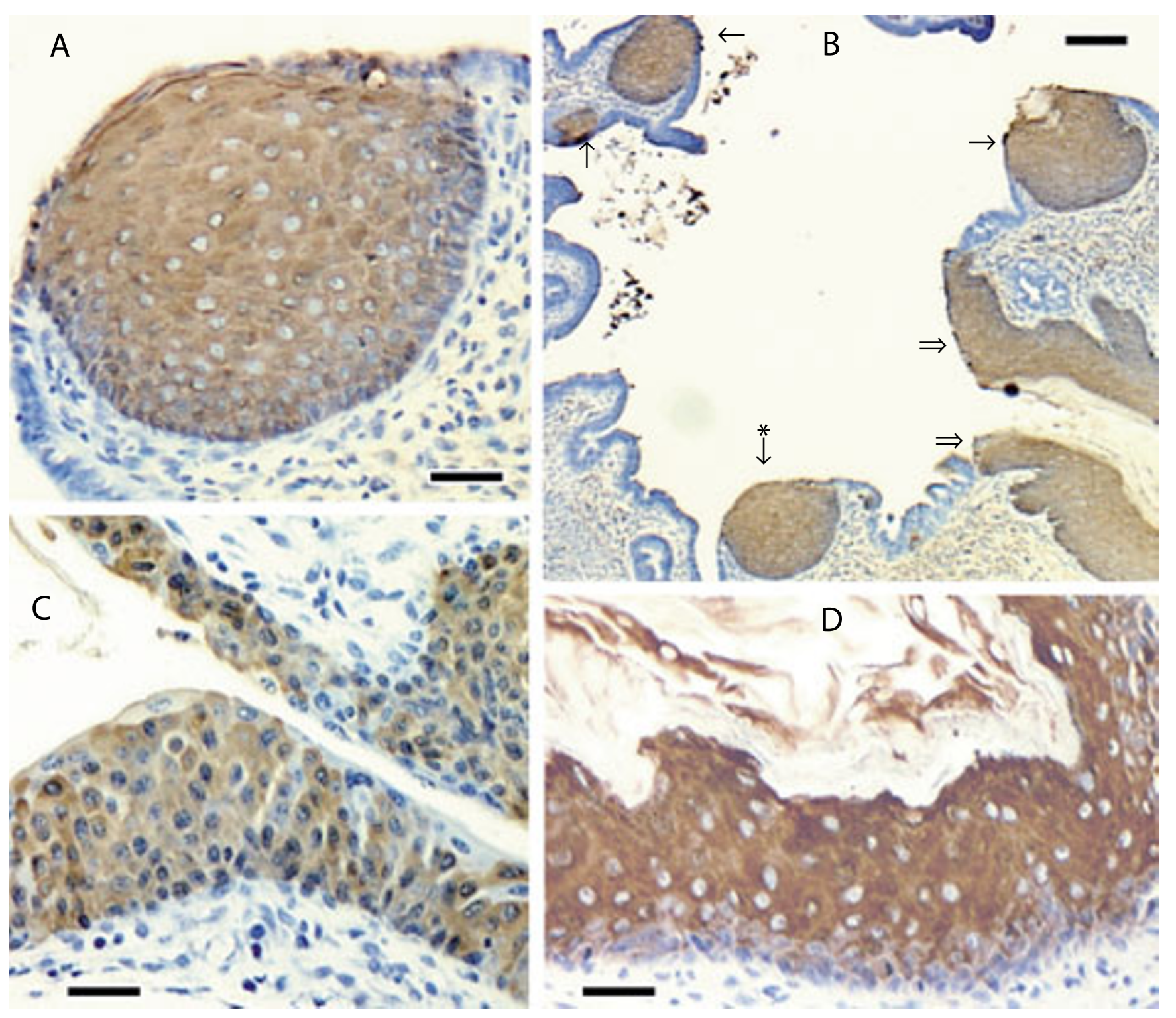

Figure 3

Immunostaining of tissues from vitamin A deprived transgenic mice Sections of female genital tract (A, B) and blad$\operatorname{der}(C, D)$ are illustrated for TG2.2/CREm (A, B, C) and TG2.2/APIm (D) mice. In panel B, double arrows point to vaginal epithelium, single arrows indicate regions of squamous metaplasia, and the asterisk indicates a metaplastic region shown at higher magnification in panel A. Scale bars: $30 \mu \mathrm{m}$ (A, C, D) and $100 \mu \mathrm{m}$ (B).

(derived from rat bladder epithelium), which gives high levels of reporter activity after transfection, and SIK cells. The latter is a cell line derived from normal human epidermis and nearly equivalent to normal cells, but with extended lifetime [22]. Fig 4 shows that in cultures of both $\mathrm{rB}$ and SIK, $2.2 \mathrm{~kb}$ and $1.6 \mathrm{~kb}$ of TGM1 promoter DNA produced similar levels of expression of the firefly luciferase reporter. Further shortening to $1.5 \mathrm{~kb}$ resulted in a substantial drop in activity in SIK cells (a three-fold effect). A smaller decrease in activity was observed in $\mathrm{rB}$ cells. A short piece of the proximal promoter (TG 0.09) had minimal activity. The region between -1.6 and -1.0 was examined more closely by progressively deleting DNA between -0.09 and $-1.6 \mathrm{~kb}$. Deletions between -0.09 and 1.4 resulted in no loss of transcriptional activity in SIK cells and half the activity in $\mathrm{rB}$ cells. In contrast, a further deletion of $100 \mathrm{bp}$ (TG 1.6-1.5) produced a dramatic 
A
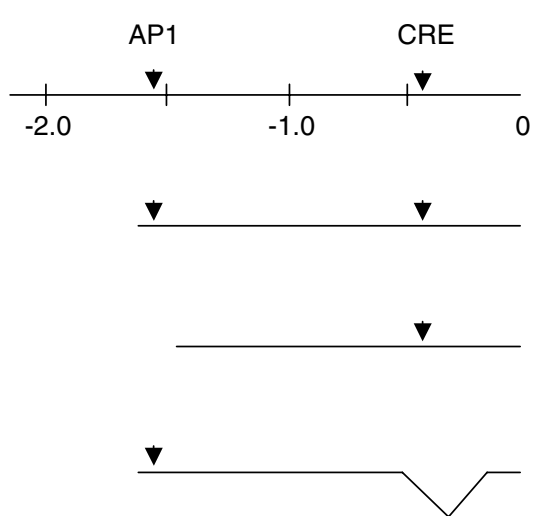

$\nabla$
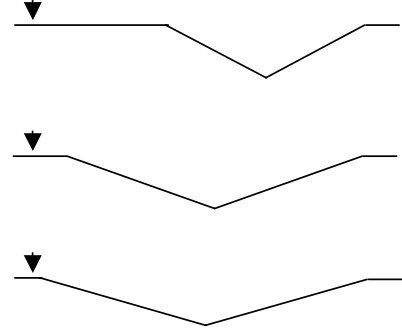

$-$
B

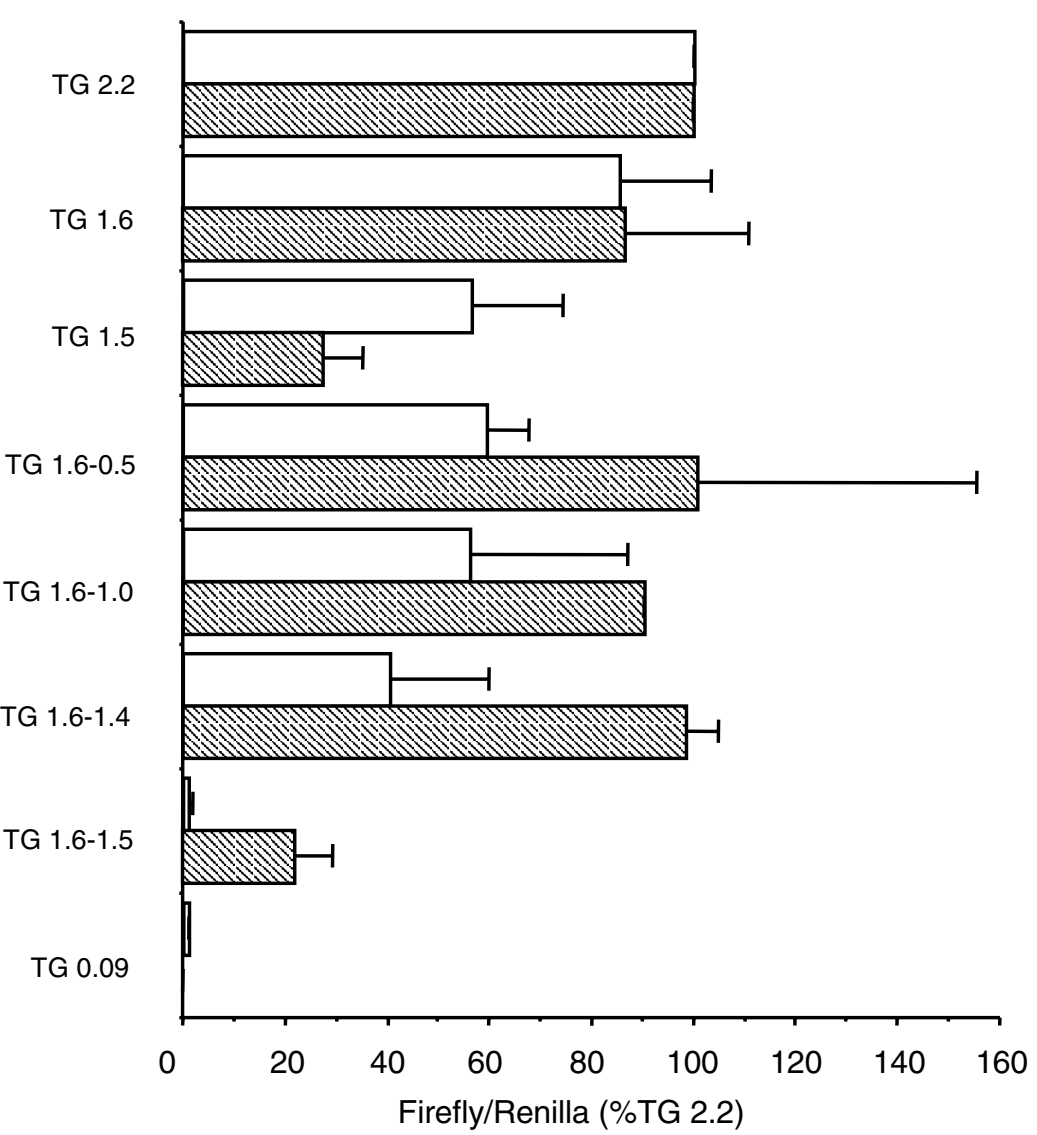

\section{Figure 4}

Transcriptional activity of TGMI distal promoter (A) At the top is shown a map of the TG $2.2 \mathrm{~kb}$ promoter with API and CRE sites indicated by arrowheads. Numbers are distances in kilobase pairs from the transcription start site (0). Shown below are schematics of 5 ' and internal deletions. Internal deletion constructs are named according to the regions of the distal promoter included. All promoters contained a small segment of the proximal promoter and the transcription start site (-90 to +67 ) and were fused to the firefly luciferase gene in plasmid pGL3. (B) Transcriptional activities of the depicted promoters were determined by transient transfection into $\mathrm{rB}$ (white bars) and SIK (filled bars) cell lines. Firefly luciferase activity was divided by the activity of a cotransfected CMV Renilla plasmid to correct for different transfection efficiencies and the result was expressed as the percentage of activity of the TG 2.2 plasmid. The means \pm SD of 2-10 independent experiments, each done in duplicate, are shown.

decrease; the activity of TG 1.6-1.5 compared to TG 1.61.4 was only $3 \%$ in $\mathrm{rB}$ and $22 \%$ in SIK cells.

\section{Detection of DNA binding proteins by EMSA}

To identify transcription factor binding sites in the transcriptionally important region between -1.5 and $-1.4 \mathrm{~kb}$, we designed overlapping EMSA probes of 25-35 bases (Fig 5A) and incubated them with nuclear extracts from SIK cells. After PAGE we observed strong DNA/protein complexes with probe G (TG -1375 to -1400) (Fig 5B). Less abundant complexes were formed using probes A
(TG -1487 to -1515 ) and C (TG -1445 to -1479) (not shown) and little if any specific binding was observed with the other probes (not shown). Inspection of the sequences of probes $A$ and $G$ suggested that the complexes might contain Sp1 transcription factors. An Sp1 consensus probe (Fig 5B, left side) produced DNA/protein complexes of similar mobilities to those obtained with TG probes A and G (Fig 5B, right side). Furthermore, the Sp1 consensus oligonucleotide competed as well or better than self competition with probes A and G. Mutation of 3 or 4 of the Sp1 core consensus G/C base pairs to A/T in 
Table 2: Comparison of TGMI promoter activities in various cultured keratinocytes

\begin{tabular}{|c|c|c|c|c|}
\hline \multirow[t]{2}{*}{ Construct } & \multicolumn{4}{|c|}{ Cell Line Transfected } \\
\hline & hEp & SIK & rEp & $r B$ \\
\hline TG 1.6 & $112 \pm 26$ & $86 \pm 24$ & $85 \pm 19$ & $85 \pm 18$ \\
\hline TG 1.5 & $46 \pm 6$ & $27 \pm 8$ & $59 \pm 7$ & $56 \pm 17$ \\
\hline TG 0.54 & $4 \pm 4$ & $7 \pm 6$ & $12 \pm 1$ & $9 \pm 5$ \\
\hline TG 2.2-0.5 & $54 \pm 1$ & $81 \pm 12$ & $49 \pm 17$ & $82 \pm 5$ \\
\hline TG 2.2-1.0 & $5 I \pm 6$ & $55 \pm 13$ & Not done & $69 \pm 37$ \\
\hline TG 2.2-1.5 & $*$ & $15 \pm 11$ & $7 \pm 9$ & $6 \pm 4$ \\
\hline
\end{tabular}

The constructs used for transfection are depicted and described in Fig 4, except that the $3^{\prime}$ deletions used in this table extended to $-2.2 \mathrm{~kb}$ instead of - I.6 kb. Firefly luciferase activity was divided by the activity of a cotransfected CMV Renilla plasmid to correct for different transfection efficiencies. To assess only the contribution of upstream sequences, the low amount of activity contributed by the proximal promoter ( $0.09 \mathrm{~kb})$ was subtracted, and the result was expressed as the percentage of activity of the TG 2.2 plasmid. The means \pm SD of 2-7 independent experiments, each done in duplicate, are shown. * Values were lower than minimal promoter alone.

both the TG-A and -G oligonucleotides and in the Sp1 consensus oligonucleotide greatly reduced their abilities to compete. Preincubation with antibody to the Sp1 or Sp3 transcription factors reduced band intensities when probed with either TG-A or TG-G (Fig 5C). Preincubation with both antibodies eliminated most of the binding. A supershifted band, indicated by an arrow, was also observed with the Sp3 antibody. An unrelated antibody did not reduce any of the DNA/protein complexes (not shown). These results show that Sp1 and Sp3 proteins account for most of the DNA-binding activity observed with these two TGM1 promoter Sp1-like sites.

Prediction of transcription factor binding sites by searching for gene sequences conserved across species, an approach called phylogenetic footprinting [31], has been developed recently as a tool for analysis of genomes [32]. This method is considered more reliable than searching for binding sites based on sequence from one species alone, since many of such identified sites cannot be shown to be biologically relevant. In addition, many regions important for transcriptional control occur as clusters of transcription factor binding sites. Therefore, sites identified in such clusters are highly likely to be functional. An alignment of four mammalian TGM1 promoters shows that the region between -1.6 and -1.4 is highly conserved across species compared to surrounding DNA (Fig 6). An additional file (see Additional File 1, File1.doc) contains an alignment of the entire $2 \mathrm{~kb}$ promoter region. The AP1 site is present in all four gene promoters. Sp1 sites A and G are conserved in human and rabbit, but not in rat and mouse, although another Sp1 site is located just 5' to site $\mathrm{G}$ in those promoters.

\section{Mutational analysis of Sp I-like sites}

The contributions of the Sp1-like sites A and G and of the upstream AP1 site to the transcriptional activity of the 1.6-1.4 region were assessed by mutagenesis and transfec- tion of the TG 1.6-1.4/pGL3 plasmid (Fig 7; see Fig 4 for diagram of TGM1 promoter included in this plasmid). In general, mutation of single sites reduced promoter activity by about half, with the exception of the TG-A site mutation in SIK cells which had little effect. Various combinations of two mutated sites further reduced activity by about half again, retaining about one quarter of the original activity, while the triple mutant retained very little activity. We conclude that nearly all the transcriptional activity in this region is attributable to a single AP1 site and two Sp1-like sites.

\section{Binding of proteins to TGMI promoter Spl-like elements during differentiation in culture}

TGM1 RNA transcripts are low in cultures of human keratinocytes before confluence, then increase at confluence, reaching a plateau by 1 week post-confluence $[27,33]$. Transcription factors that are important for mediating this process might follow a similar time course. To determine the levels of TGM1 promoter Sp1-like binding proteins during various stages of growth, nuclear extracts were prepared from SCC9 and SIK cultures before confluence, at confluence and 1 (SCC9 only) and 2 weeks after confluence, then incubated with the Sp1-like probes TG-A and TG-G for EMSA analysis. Binding activities in extracts from SCC9 were lower in growing cells, then increased dramatically at confluence and were maintained thereafter (Fig 8). SIK nuclear extract binding activity increased more modestly after confluence, particularly noticeable in the experiment using probe TG-G.

\section{Discussion}

Completion of the human genome sequence has generated renewed interest in determining which elements in the vast stretches of intergenic DNA are important for regulation of transcription. So far this is still not possible to predict based on sequence alone. Rather, experiments are required to test the abilities of different regions of gene 
A

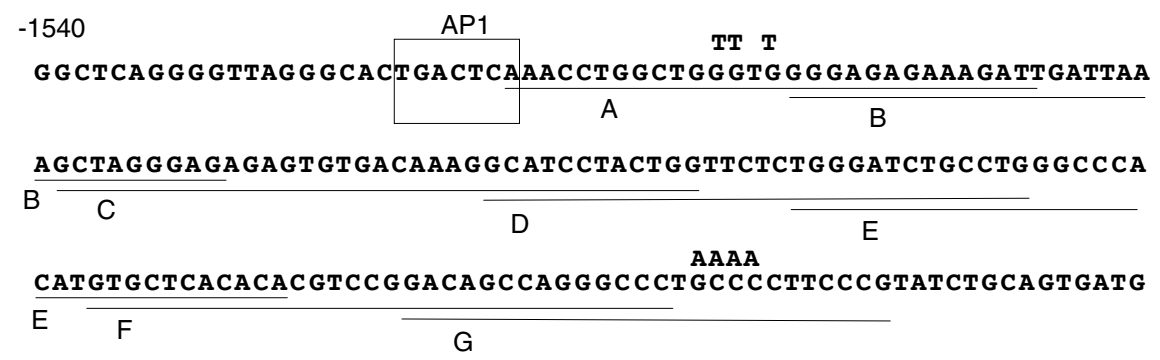

B

Probe

Sp1

TG-G

TG-A

Competitor
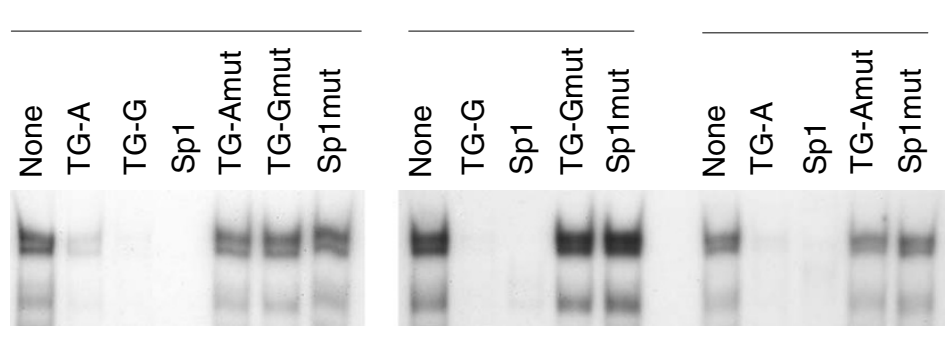

C

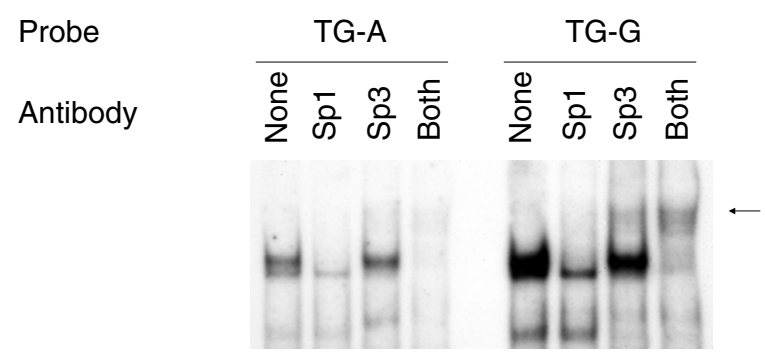

\section{Figure 5}

Binding activities of keratinocyte nuclear proteins to SPI-like sequences $A$ ) The sequence of the TGMI promoter from - I540 to - I36I kb is shown. The overlapping underlined sequences labelled A-G were chosen as EMSA probes. Both strands were synthesized and annealed, leaving a single $G 5^{\prime}$ overhang to allow labelling with ${ }^{32} \mathrm{P}$ dCTP by a fill-in reaction. In some cases an additional $G$ residue, not present in the gene sequence, was included at the 5 ' end of one strand. The $T$ and $A$ residues written above some bases in probes $A$ and $G$ indicate the base changes to make the mutants, TG-Amut and TGGmut. B) Probes were a consensus SpI site (Stratagene) or TGMI promoter SpI-like sites, TG-A and TG-G. Competitors were added as indicated or None for no competitor. To make the mutant consensus Spl site (Splmut), the core sequence GGGGCGGGG was changed to GGTTTTGGG. Nuclear extracts were from postconfluent SIK cells. C) Antibodies to SpI, $\mathrm{Sp3}$ or both were added as indicated to binding reactions with nuclear extracts from postconfluent SIK cells before addition of probes TG-A or TG-G. The no antibody control is indicated by None. An arrow shows a supershifted band visible after addition of Sp3 antibody.

promoters to regulate transcription appropriately. Common patterns may then emerge to explain such features as cell-specific expression. Studying the regulation of genes expressed specifically in keratinocytes has led to the identification of several transcription factors commonly associated with this process [34]. As yet, no predictable patterns have emerged, necessitating the continued use of a gene by gene approach for the elucidation of keratinocyte-specific gene regulatory regions.
We have concentrated on regulation of the TGM1 gene in keratinocyte cultures and in transgenic mice. While our work was in progress, reports appeared that a $2.5 \mathrm{~kb}$ region upstream of the human TGM1 coding region was sufficient to confer appropriate expression of a linked reporter in transgenic mice [13] and a $2.9 \mathrm{~kb}$ upstream region of the rabbit TGM1 gene acted similarly [12]. Our further studies have narrowed the minimum length of necessary promoter DNA to between 1.6 and $1.1 \mathrm{~kb}$ 


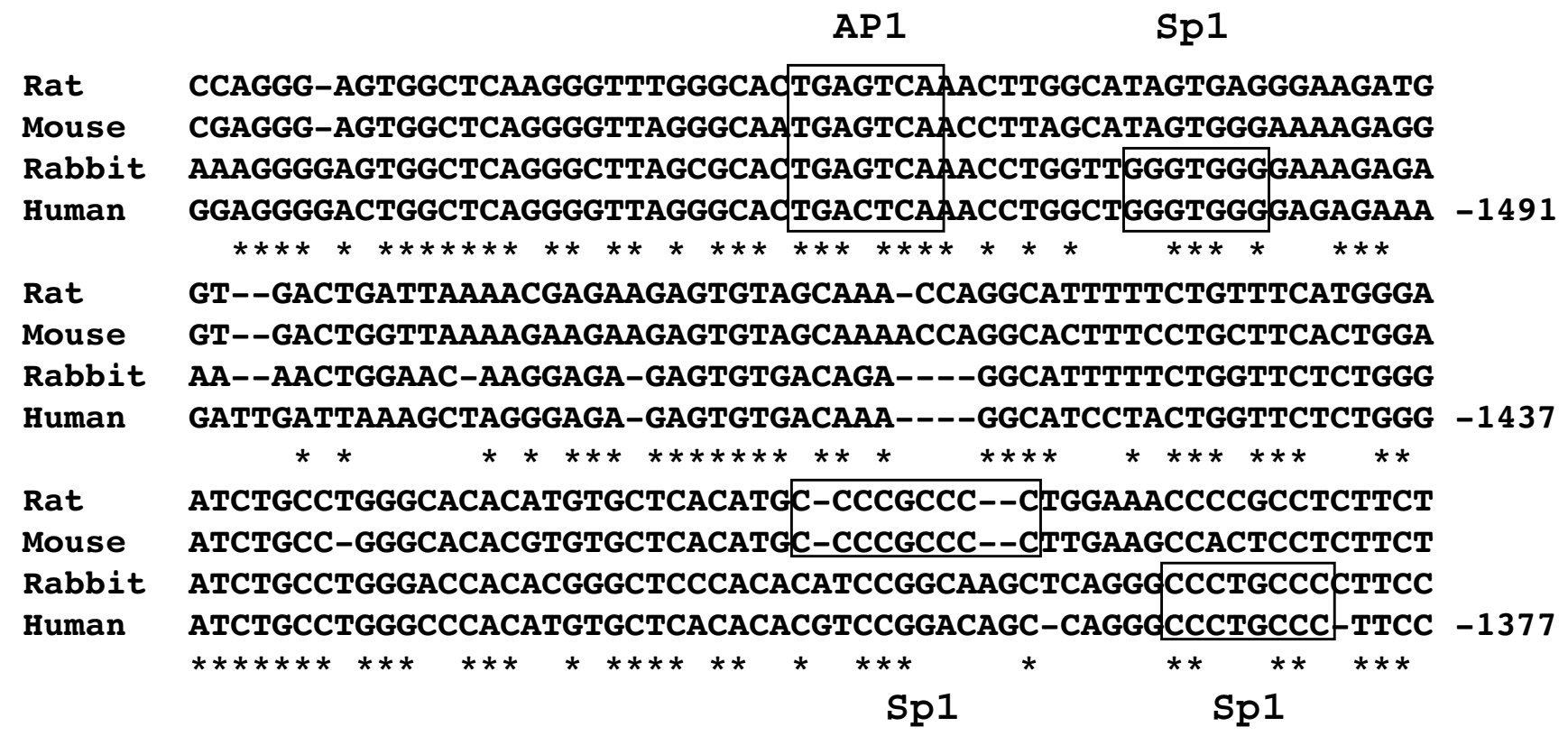

Figure 6

Alignment of human, rat, mouse and rabbit TGMI promoters Sequences were aligned using the ClustalW program. Sources of DNA sequence are: human, Genbank AF00563I, M83 I 20 and our unpublished sequence; rabbit, LI07I5; rat, AF309647; mouse, NCBI mouse genome project, chromosome I4 TGMI gene. Boxes show identified transcription factor binding sites and $*$ indicates that the nucleotide in that position is conserved in all four species. Numbers refer to distance in base pairs from the transcription start site of the human gene, assigned as 0 .

upstream of the transcription start site. That the required promoter region is rather short probably reflects the close proximity of the upstream Rab geranylgeranyl transferase gene [35,36]. Alignments of human, rabbit, rat and mouse promoters show several regions that are well conserved. These include regions containing previously identified CRE [12,14] and AP1 [14] sites. Mutation of either of these sites to sequences shown in vitro to destroy DNA binding activity did not prevent appropriate expression of the reporter gene in most of the founder lines harboring the mutations. This finding suggests that, although these sites contribute to transcription of the TGM1 gene in transfection assays with cultured cells $[12,14]$, there must be compensatory mechanisms for their loss. This is in contrast to the loss of expression due to mutation of AP1 sites in the loricrin [37] and involucrin [38] gene promoters. Although some transgenic founder lines harboring the mutated TGM1 promoters exhibited correct expression patterns, this was not the case for all of the founder lines and is in contrast to the TG2.2 mice in which high levels of tissue specific expression were seen in 6 of 6 founder lines. Only 1 of 3 TG2.2AP1mut founder lines exhibited high levels of reporter expression, leaving open the possibility that this element contributes to tran- scriptional efficiency of the promoter. This is difficult to conclude decisively in transgenic animals due to the contribution of the integration site to transcription levels even when the copy number inserted is known and rearrangements are not evident. The CRE mutation, on the other hand, did not appear to affect levels of transcription, although low levels of ectopic expression were noted in the mutants. Therefore, that element may have a role in preventing gene expression in tissues where it is not normally expressed.

TGM1 is expressed normally during the process of squamous differentiation [9,39] and in addition is one of the markers associated with squamous metaplasia, a process that occurs in several tissues as a result of pathological processes, including vitamin A deficiency [10]. Since sites of metaplasia in regions of toxic insult can progress to neoplasias (e.g., in the upper airways as a result of smoking), understanding of the metaplastic process may assist in cancer prevention, diagnosis and treatment. In addition to identifying genes that are induced during squamous metaplasia, we are now in a position to determine the transcriptional mechanisms that lead to adoption of the metaplastic phenotype. As a beginning, we asked whether 


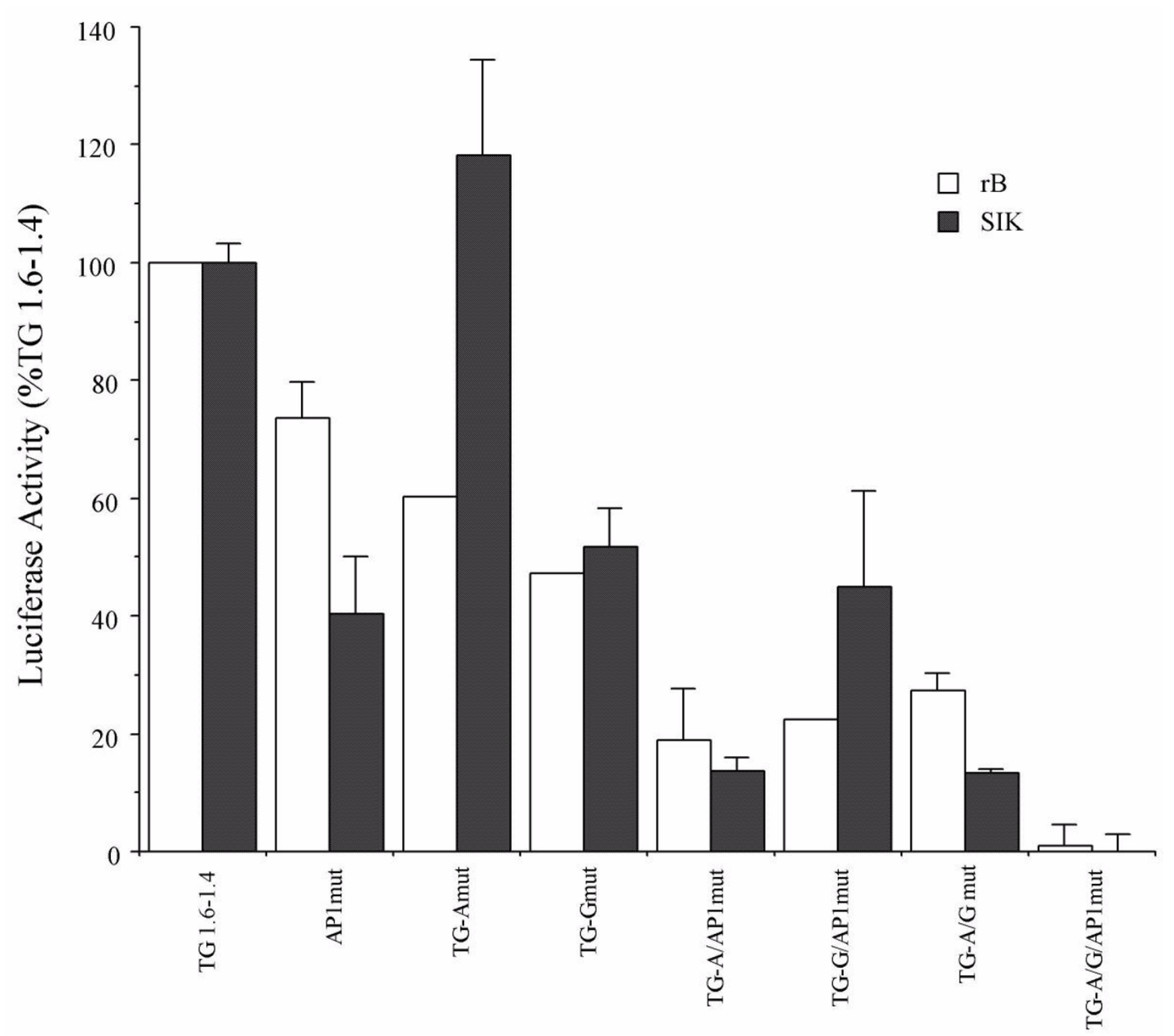

\section{Figure 7}

Transcriptional activities of SPI and API mutants Mutations were introduced into TG I.6-I.4 by site-directed mutagenesis and assayed by transient transfection into rB (white bars) and SIK (filled bars) cell lines. The promoter with no mutations is designated as TGI.6-I.4; mutant promoters are named according to the sites mutated. Firefly luciferase values were normalized to the value of a cotransfected PRL-CMV plasmid. To assess only the contribution of the distal promoter, the small amount of activity contributed by the short piece of the proximal promoter $(0.09$ to +67$)$ was subtracted, and the data are expressed as the percentage of the value obtained from the plasmid without mutations (TGI.6-I.4, designated as I00\%). Means and SD of a representative experiment are shown. The experiment was performed 3 times with rB cells and 4 times with SIK cells.

the same TGM1 promoter elements that drive reporter expression in normal stratified epithelia of transgenic mice would be sufficient for expression in metaplastic tissue as well. The results suggest that the regulation of the metaplastic process involves use of the same response elements and perhaps even induction of the same transcription factors that are present in normal stratified tissues. This was not necessarily predictable as the process might have occurred using different transcription factors acting at distinct promoter elements. 


\begin{abstract}
NE $\quad$ SCC9
SIK

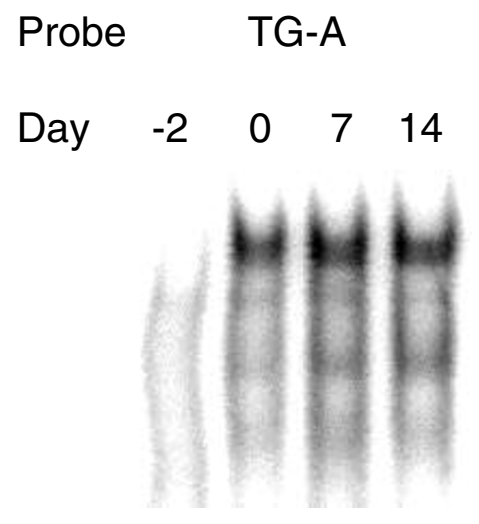

TG-G

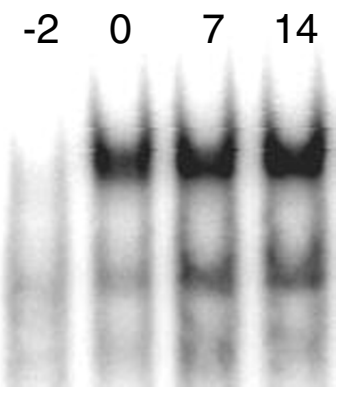

TG-A

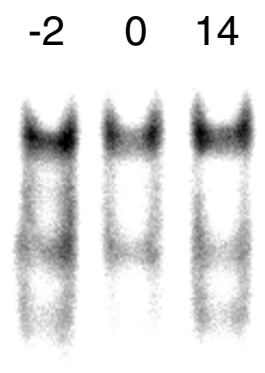

TG-G

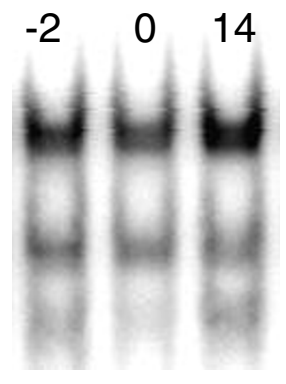

\section{Figure 8}

Binding activities of keratinocyte nuclear extracts as a function of differentiation state Keratinocyte nuclear extracts (NE) were prepared from SCC9 and SIK cultures which were preconfluent (Day -2), confluent (Day 0) or post-confluent (Days 7 and 14). Equal amounts of protein were incubated with TG-A and TG-G probes, and binding activities were determined by EMSA.
\end{abstract}

The importance of the human TGM1 promoter region from -1.6 to $-1.1 \mathrm{~kb}$ for expression in transgenic mice led us to focus on identifying transcription factors that bind to this region. This is most easily done by first using transfections of cultured cells, then re-testing more precisely defined promoters in transgenic mice. The availability of cell culture models that exhibit many of the features of the normal differentiation process is essential for this work. In this case we have primarily used a spontaneously immortalized human keratinocyte line (SIK) and a line of keratinocytes derived from rat bladder epithelium (rB). The latter have the advantage that they are easily transfected and express high levels of reporter activity. The major conclusions are the same for both cell lines: (1) we have identified a 200 bp region, from -1.6 to -1.4 that is required for 40 to $100 \%$ of the activity of the $1.6 \mathrm{~kb}$ promoter in $\mathrm{rB}$ and SIK cells, respectively; and (2) mutational analysis showed that AP1 and Sp1 binding sites account for most of the transcriptional activity of that region. Some quantitative differences were noted in the effects of certain deletions and mutations in the two cell lines, e.g. muta- tion of the TG-A site suppresses activity in $\mathrm{rB}$ cells but not in the SIK line (Fig 7); however, these differences do not affect our overall conclusions.

AP1 and Sp1 family transcription factor binding sites are commonly found in keratinocyte-specific genes. Since members of these transcription factor families are widely expressed, it is not yet understood how keratinocyte-specific expression is achieved, although it should be noted that keratinocytes have unusually high levels of both factors and that overexpression of Sp1 in fibroblasts reportedly activates expression of a transfected involucrin promoter [40]. Furthermore, we found that binding of keratinocyte nuclear proteins to TGM1 Sp1-like binding sites increased as the cells progressed in their differentiation program with time in culture, as might be expected if the abundance of these proteins is critical for initiating TGM1 transcription. This was most dramatic in SCC9 cells, which exhibit a strong induction of differentiation markers (including TGM1) at confluence ([27] and earlier work). Our results agree with others who have observed 
sustained or increased Sp1/Sp3 binding activity upon differentiation of keratinocytes derived from mouse epidermis, rabbit cornea and the human epidermal-derived HaCat cell line [41-46]. Specificity of gene expression may lie in the arrangement of sites or in cooperation with other as yet unidentified keratinocyte-specific factors. It may be noteworthy that, although various computer algorithms for predicting transcription factor binding sites identified the AP1 and Sp1 sites, other regions of sequence conservation were not identified as binding sites for known factors and remain to be explored as potential response elements for keratinocyte-specific factors.

Alignment of TGM1 promoters from four species also points to the -1.6 to $-1.4 \mathrm{~kb}$ region as potentially important for transcriptional regulation since much of the sequence in that region is conserved. However, an important difference in the location of Sp1 binding sites between rodents and human and rabbit is evident. The distal Sp1 site has been eliminated in the rodent lineage and the location of the proximal site is slightly shifted. The importance of these differences has yet to be explored, but may contribute to differences we have seen in some aspects of regulation of the endogenous TGM1 gene in human and rat cell lines (BAJ, unpublished data).

\section{Conclusions}

The distal region of the TGM1 gene promoter was shown to be required for appropriate expression of a linked reporter in transgenic mice both in normal squamous tissues and in squamous metaplasia. A 200 bp region from 1.6 to $-1.4 \mathrm{~kb}$ upstream of the transcription start site was determined to be responsible for a majority of the transcriptional activity of the promoter in transfection assays and is largely conserved in sequence across four mammalian species. This region contains AP1 and Sp1 transcription factor binding sites, and mutation of all three sites destroys nearly all the transcriptional activity.

\section{Competing interests}

None declared.

\section{Authors' contributions}

Major contributions of the authors are as follows: MAP: Westerns, transfections, EMSA assays, compilation of results and drafting manuscript; BAJ: methods development and evaluation of TG 2.2 mice; YL: immunostaining and vitamin A deprivation studies; QQ: transgenic screening and transfections; MES: production of initial transgenic mouse lines; RHR: project design and supervision. All authors read and approved the manuscript.

\section{Additional material}

\section{Additional File 1}

Alignment of $2 \mathrm{~kb}$ upstream region of human, rat, mouse and rabbit TGM1 genes. Sequences were aligned using the ClustalW program. Sources of DNA sequence are: human, Genbank AF005631, M83120 and our unpublished sequence; rabbit, L10715; rat, AF309647; mouse, NCBI mouse genome project, chromosome 14 TGM1 gene. Numbers refer to the number of base pairs from the beginning of the downloaded DNA sequences. They are retained in this figure so that the reader may calculate the distance from the transcription start sites, which for the human gene has been mapped to position 2204 in the sequence shown.

Click here for file

[http://www.biomedcentral.com/content/supplementary/14715945-4-2-S1.doc]

\section{Acknowledgements}

We thank the UC Davis Targeted Genomics Lab for preparing some transgenic mice, Dr. Charles Stephensen for advice on vitamin A deprivation and Ms. Lauren Stevens for assisting in mouse handling. This research was supported by USPHS grants ROI AR27 I 30, T32 ES07059, P42 ES04699 and P30 ES05707.

\section{References}

I. Greenberg CS, Birckbichler PJ, Rice RH: Transglutaminases: Multifunctional enzymes that stabilize tissues. FASEB Journal I991, 5:307| -3077.

2. Jeon S, Djian P, Green H: Inability of keratinocytes lacking their specific transglutaminase to form cross-linked envelopes: absence of envelopes as a simple diagnostic test for lamellar ichthyosis. Proceedings of the National Academy of Sciences USA 1998 , 95:687-690.

3. Huber M, Rettler I, Bernasconi K, Frenk E, Lavrijsen SPM, Ponec M, Bon A, Lautenschlager S, Schorderet DF, Hohl D: Mutations of keratinocyte transglutaminase in lamellar ichthyosis. Science 1995, 267:525-528.

4. Parmentier L, Blanchet-Bardon C, Nguyen S, Prud'homme J-F, Dubertret L, Weissenbach J: Autosomal recessive lamellar ichthyosis: identification of a new mutation in transglutaminase $I$ and evidence for genetic heterogeneity. Human Molecular Genetics 1995, 4:1391-1395.

5. Russell LJ, DiGiovanna JJ, Rogers GR, Steinert PM, Hashem N, Compton JG, Bale SJ: Mutations in the gene for transglutaminase I in autosomal recessive lamellar ichthyosis. Nature Genetics 1995, 9:279-283.

6. Elias PM, Schmuth M, Uchida Y, Rice RH, Behne M, Crumrine D, Feingold KR, Holleran WM: Basis for the permeability barrier abnormality in lamellar ichthyosis. Experimental Dermatology 2002, II:248-256.

7. Petit E, Huber M, Rochat A, Bodemer C, Teillac-Hamel D, Muh J-P, Revuz J, Barrandon $Y$, Lathrop M, de Prost $Y$, Hohl D, Hovnanian A: Three novel point mutations in the keratinocyte transglutaminase (TGK) gene in lamellar ichthyosis: Significance for mutant transcript level, TGK immunodetection and activity. European Journal of Human Genetics 1997, 5:218-228.

8. Jessen BA, Phillips MA, Hovnanian A, Rice RH: Role of Sp I response element in transcription of the human transglutaminase I gene. Journal of Investigative Dermatology 2000, i 15:113-117.

9. Parenteau NL, Pilato A, Rice RH: Induction of keratinocyte typeI transglutaminase in epithelial cells of the rat. Differentiation 1986, 33:|30-|4|.

10. Jetten AM, Brody AR, Deas MA, Hook GER, Rearick JI, Thacher SM: Retinoic acid and substratum regulate the differentiation of rabbit tracheal epithelial cells into squamous and secretory phenotype. Laboratory Investigation 1987, 56:654-664. 
11. Phillips MA, Rice RH: Convergent differentiation in cultured rat cells from nonkeratinizing epithelia: Keratinocyte character and intrinsic differences. Journal of Cell Biology 1983, 97:686-69I.

12. Medvedev A, Saunders NA, Matsuura H, Chistokhina A, Jetten AM Regulation of the transglutaminase I gene: Identification of DNA elements involved in its transcriptional control in tracheobronchial epithelial cells. Journal of Biological Chemistry 1999, 274:3887-3896

13. Yamada K, Matsuki M, Morishima Y, Ueda E, Tabata K, Yasuno H, Suzuki M, Yamanishi K: Activation of the human transglutaminase I promoter in transgenic mice: terminal differentiation-specific expression of the TGMI-lacZ trransgene in keratinized stratified squamous epithelia. Human Molecular Genetics 1997, 6:2223-2231.

14. Jessen BA, Qin Q, Rice RH: Functional API and CRE response elements in the human keratinocyte transglutaminase promoter mediating Whn suppression. Gene 2000, 254:77-85.

15. Mariniello L, Qin Q, Jessen BA, Rice RH: Keratinocyte transglutaminase promoter analysis: Identification of a functional repsonse element. Journal of Biological Chemistry 1995 , 270:3|358-3|363.

16. Eckert RL, Green H: Structure and evolution of the human involucrin gene. Cell 1986, 46:583-589.

17. Phillips MA, Stewart BE, Rice RH: Genomic structure of keratinocyte transglutaminase: Recruitment of new exon for modified function. Journal of Biological Chemistry 1992, 267:2282-2286.

18. Couse JF, Davis VL, Tally WC, Korach KS: An improved method of genomic DNA extraction for screening transgenic mice. Biotechniques 1994, I 7:1030-1032.

19. Bradford MM: A rapid and sensitive method for the quantitation of microgram quantities of protein using the principle of protein-dye binding. Analytical Biochemistry 1976, 72:248-254.

20. Murphy GF, Flynn TC, Rice RH, Pinkus GS: Involucrin expression in normal and neoplastic human skin: a marker for keratinocyte differentiation. Journal of Investigative Dermatology 1984, 82:453-457.

21. Rice RH, Green H: Presence in human epidermal cells of a soluble protein precursor of the cross-linked envelope: Activation of the cross-linking process by calcium ions. Cell 1979, | 8:68|-194.

22. Rice RH, Steinmann KE, deGraffenried LA, Qin Q, Taylor N, Schlegel $\mathrm{R}$ : Elevation of cell cycle control proteins during spontaneous immortalization of human keratinocytes. Molecular Biology of the Cell 1993, 4:185-194

23. Rheinwald JG, Beckett MA: Tumorigenic keratinocyte lines requiring anchorage and fibroblast support cultured from human squamous carcinomas. Cancer Research 1981, 41:1657-1663

24. Heimann R, Rice RH: Rat esophageal and epidermal keratinocytes: Intrinsic differences in culture and derivation of continuous lines. Journal of Cellular Physiology 1983, I I 7:362-367.

25. Rheinwald JG, Green H: Serial cultivation of strains of human epidermal keratinocytes: The formation of keratinizing colonies from single cells. Cell 1975, 6:331-344

26. Allen-Hoffmann BL, Rheinwald JG: Polycyclic aromatic hydrocarbon mutagenesis of human epidermal keratinocytes in culture. Proc Nat Acad of Sci USA 1984, 8 I:7802-7806.

27. Jessen BA, Qin Q, Phillips MA, Phillips DL, Rice RH: Keratinocyte differentiation marker suppression by arsenic: Mediation by API response elements and antagonism by tetradecanoylphorbol acetate. Toxicology and Applied Pharmacology 2001, I 74:302-3II.

28. Gorman CM: High efficiency gene transfer into mammalian cells. DNA Cloning, A Practical Approach Volume 2. Edited by: Glover D M. Oxford, IRL Press; 1985:I43-190.

29. Dignam JD, Lebovitz RM, Roeder RG: Accurate transcription initiation by RNA polymerase II in a soluble extract from isolated mammalian nuclei. Nucleic Acids Research 1983, I I:|475-1489.

30. Phillips MA, Qin Q, Rice RH: Identification of an involucrin promoter transcriptional response element with activity restricted to keratinocytes. Biochemical Journal 2000, 348:45-53.

31. Tagle DA, Koop BF, Goodman M, Slightom JL, Hess DL, Jones RT: Embryonic $e$ and $g$ globin genes of a prosimian primate (Galago crassicaudatus). Nucleotide and amino acid sequences, developmental regulation and phylogenetic footprints. Journal of Molecular Biology 1988, 203:439-455.

32. Lenhard B, Sandelin A, Mendoza L, Engstrom P, Jareborg N, Wasserman WW: Identification of conserved regulatory elements by comparative genome analysis. Journal of Biology 2003, 2: 13.

33. Mazina OM, Phillips MA, Williams T, Vines CA, Cherr GN, Rice RH: Redistribution of transcription factor AP-2alpha in differentiating cultured human epidermal cells. Journal of Investigative Dermatology 200 I, I I 7:864-870.

34. Eckert RL, Crish JF, Banks EB, Welter JF: The epidermis: Genes on - genes off. Journal of Investigative Dermatology I997, I 09:50 I-509.

35. van Bokhoven H, Rawson RB, Merkx GFM, Cremers FPM, Seabra MC: cDNA cloning and chromosomal localization of the genes encoding the $a-$ and $b$-subunits of human Rab geranylgeranyl transferase: the 3' end of the a-subunit gene overlaps with the transglutaminase I gene promoter. Genomics 1996, 38: $133-140$.

36. Song H-J, Rossi A, Ceci R, Kim I-N, Anzano MA, Jang S-I, De Laurenzi $\checkmark$, Steinert PM: The genes encoding geranylgeranyl transferase a-subunit and transglutaminase I are very closely linked but not functionally related in terminally differentiating keratinocytes. Biochemical and Biophysical Research Communications 1997, 235:10-14.

37. DiSepio D, Bickenbach JR, Longley MA, Bundman DS, Rothnagel JA, Roop R: Characterization of loricrin regulation in vitro and in transgenic mice. Differentiation 1999, 64:225-235.

38. Crish JF, Bone F, Banks EB, Eckert RL: The human involucrin gene contains spatially distinct regulatory elements that regulate expression during early versus late epidermal differentiation. Oncogene 2002, 2 I :738-747.

39. Thacher SM, Rice RH: Keratinocyte-specific transglutaminase of cultured human epidermal cells: Relation to cross-linked envelope formation and terminal differentiation. Cell 1985 , 40:685-695.

40. Banks EB, Crish JF, Eckert RL: Transcription factor Sp I activates involucrin promoter activity in non-epithelial cell types. Biochemical Journal 1999, 337:507-5 12.

41. Prowse DM, Bolgan L, Molnar A, Dotto GP: Involvement of the Sp3 transcription factor in induction of p2 ICip I/WAFI in keratinocyte differentiation. Journal of Biological Chemistry 1997, 272: $|308-13| 4$

42. Park GT, Morasso MI: Regulation of the Dlx3 homeobox gene upon differentiation of mouse keratinocytes. Journal of Biological Chemistry 1999, 274:26599-26608.

43. Jang S-I, Steinert PM: Loricrin expression in cultured human keratinocytes is controlled by a complex interplay between transcription factors of the SpI, CREB, API, and AP2 families. Journal of Biological Chemistry 2002, 277:42268-42279.

44. Chen T-T, Wu R-L, Castro-Munozledo F, Sun T-T: Regulation of K3 keratin gene transcription by SpI and AP-2 in differentiating rabbit corneal epithelial cells. Molecular and Cellular Biology 1997, I 7:3056-3064.

45. Apt D, Watts RM, Suske G, Bernard H-U: High Spl/Sp3 ratios in epithelial cells during epithelial differentiation and cellular transformation correlate with the activation of the HPV-I 6 promoter. Virology 1996, 224:281-291.

46. Maatta A, Ruhrberg C, Watt FM: Structure and regulation of the envoplakin gene. Journal of Biological Chemistry 2000, 275: $19857-19865$.

\section{Pre-publication history}

The pre-publication history for this paper can be accessed here:

http://www.biomedcentral.com/1471-5945/4/2/prepub 